\title{
Artemisinin Ameliorates Osteoarthritis by Inhibiting the Wnt/ $\beta$-Catenin Signaling Pathway
}

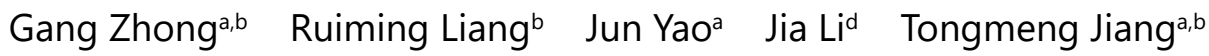 \\ Jianwei Liu ${ }^{a, b}$ Yiguan Le ${ }^{a, b} \quad$ Chong Shen ${ }^{a, b}$ Huiping Long ${ }^{c}$ Huiping Lu ${ }^{a}$ \\ Shiting Ma ${ }^{a}$ Jun Luo ${ }^{b} \quad$ Zhikang Miao ${ }^{b}$ Wei Su,b Li Zheng $^{\mathrm{b}}$ \\ Jinmin Zhao a,b
}

aDepartment of Orthopaedics Trauma and Hand Surgery \& Guangxi Key Laboratory of Regenerative Medicine, International Joint Laboratory on Regeneration of Bone and Soft Tissue, The First Affiliated Hospital of Guangxi Medical University, Nanning, ' ${ }^{b}$ Guangxi Engineering Center in Biomedical Materials for Tissue and Organ Regeneration \& Guangxi Collaborative Innovation Center for Biomedicine, The First Affiliated Hospital of Guangxi Medical University, Nanning, 'Department of Neurology, The Second Affiliated Hospital of Guangxi Medical University, Guangxi Medical University, Nanning, dDepartment of Pathology, The First Affiliated Hospital of Guangxi Medical University, Nanning, China

\section{Key Words}

Artemisinin • Osteoarthritis • Wnt/ $\beta$-catenin signaling pathway

\begin{abstract}
Background/Aims: Current drug therapies for osteoarthritis (OA) are not practical because of the cytotoxicity and severe side-effects associated with most of them. Artemisinin (ART), an antimalarial agent, is well known for its safety and selectivity to kill injured cells. Based on its anti-inflammatory activity and role in the inhibition of OA-associated Wnt/ $\beta$-catenin signaling pathway, which is crucial in the pathogenesis of OA, we hypothesized that ART might have an effect on OA. Methods: The chondro-protective and antiarthritic effects of ART on interleukin1-beta (IL-1 $\beta$ )-induced and OA patient-derived chondrocytes were investigated in vitro using cell viability assay, glycosaminoglycan secretion, immunofluorescence, quantitative reverse transcription-polymerase chain reaction, and western blotting. We also used OA model rats constructed by anterior cruciate ligament transection and medial meniscus resection $(A C L T+M M x)$ in the joints to investigate the effects of ART on OA by gross observation, morphological staining, immunohistochemistry, and enzyme-linked immunosorbent assay. Results: ART exhibited potent anti-inflammatory effects by inhibiting the expression of proinflammatory chemokines and cytokines, including interleukin (IL)-1 $\beta, \mathrm{IL}-6$, tumor necrosis factor alpha, and matrix metallopeptidase-13. It also showed favorable chondro-protective effect as evidenced by enhanced cell proliferation and viability, increased glycosaminoglycan
\end{abstract}

G. Zhongm R. Liang and J. Yao contributed equally to this work.

Wei Su

and Li Zheng 
deposition, prevention of chondrocyte apoptosis, and degeneration of cartilage. Further, ART inhibited OA progression and cartilage degradation via the $\mathrm{Wnt} / \beta$-catenin signaling pathway, suggesting that it might serve as a Wnt/ $\beta$-catenin antagonist to reduce inflammation and prevent cartilage degradation. Conclusion: In conclusion, ART alleviates IL-1 $\beta$-mediated inflammatory response and OA progression by regulating the $W n t / \beta$-catenin signaling pathway. Thereby, it might be developed as a potential therapeutic agent for OA.

(C) 2018 The Author(s)

Published by S. Karger AG, Basel

\section{Introduction}

Osteoarthritis $(\mathrm{OA})$ is one of the most painful, prevalent articular disorders that affects $10 \%-15 \%$ of adults, and it becomes a burden to patients, communities, and health and social care systems [1]. Osteoarthritis is characterized by progressive articular cartilage degeneration, synovial inflammation, and subchondral bone damage. Currently, effective therapy for $\mathrm{OA}$ is limited. Non-pharmacologic and non-surgical therapies, including therapeutic ultrasound and terminal isometric exercises, are introduced to treat OA [2]. Current therapy for $\mathrm{OA}$ is based on a sequential hierarchical approach, with non-steroidal anti-inflammatory drugs (NSAIDs) as the leading treatment option [3]. Although they exhibit effective pain reduction, the treatment with NSAIDs is limited by complications such as gastroenteropathy, ease of suppression, limited clinical remission rate, immunity, and secondary tumors $[4,5]$. An alternative is natural anti-inflammatory agents derived from plants and herbs, such as olive oil, icariin, and angelica polysaccharides, which have potential to prevent cartilage degeneration in patients with $\mathrm{OA}[6,7]$.

Artemisinin (ART) is a sesquiterpene lactone isolated from the Chinese plant Artemisia annua (commonly known as qinghaosu or sweet wormwood) in 1970 by Youyou Tu, who was awarded the Nobel Prize in Physiology or Medicine in 2015 [8]. Artemisinin and its derivatives are currently identified as the most effective drugs to treat chloroquine-resistant $[9,10]$. In addition, with minimal side effects and nonresistant characteristics, ART can selectively kill parasite-infected red blood cells, but preserve the healthy cells $[11,12]$. This unique pharmacological mechanism endows ART distinct advantages of efficacy and safety in clinical application. Besides the anti-malarial functions, ART family drugs also exhibit anti-tumor [13-15], anti-viral [16], anti-inflammatory, and immune-suppressive activities $[17,18]$. Artemisinin has been reported to abolish germinal center B cells and inhibit autoimmune arthritis in the K/BxN mouse model of rheumatoid arthritis [19]. SM905, a kind of ART derivative, ameliorates collagen-induced arthritis by suppressing inflammatory response [20]. These findings indicate that ART might have potential in the treatment of joint inflammation in patients with $\mathrm{OA}$, which should be further verified.

Evidence also suggests that ART exerts anti-inflammatory and anti-tumor effects by suppressing the Wnt/ $\beta$-catenin signaling pathway, which is well established as a crucial pathway regulating the pathogenesis of OA $[21,22]$. The canonical Wnt pathway triggers its signaling within chondrocytes by regulating intracellular level and subcellular localization of $\beta$-catenin $[23,24]$. As a pivotal factor in the noncanonical Wnt pathway, Wnt5a can also activate canonical $\beta$-catenin signaling, which contributes to the therapeutic effect on OA [25]. Conditional activation of $\beta$-catenin by Wnt5a in articular chondrocytes from adult mice leads to premature chondrocyte differentiation and development OA-like phenotype development, including progressive loss of articular cartilage matrix and formation of osteophytes [26, 27]. Given the importance of Wnt/ $\beta$-catenin signaling pathway in $O A$ progression, $W n t / \beta$ catenin antagonists, such as sclerostin (SOST) and verapamil, are used to treat OA [28]. Thus, the ART drugs might be developed as novel Wnt/ $\beta$-catenin antagonist for OA.

In this study, we explored the effect of ART on OA and its association with Wnt/ $\beta$ catenin signaling by evaluating cell apoptosis- and inflammation related-markers in OA chondrocytes derived from interleukin (IL)-1 $\beta$-induced animal models or human patients. Further investigation on the effects of ART on OA in vivo was also carried out using the joints 


\section{Cellular Physiology Cell Physiol Biochem 2018;51:2575-2590 \begin{tabular}{ll|l} 
and Biochemistry Published onlIne: T1 December 2018 & $\begin{array}{l}\text { @ } 2018 \text { The Author(s). Published by S. Karger AG, Basel } \\
\text { www.karger.com/cpb }\end{array}$ \\
\hline
\end{tabular} \\ Zhong et al.: Artemisinin Ameliorates Osteoarthritis}

of ACLT+MMx stimulated rats. This study might provide novel insights on the use of ART in the treatment and prevention of $\mathrm{OA}$.

\section{Materials and Methods}

\section{Material}

Artemisinin was purchased from Sigma-Aldrich(Shanghai, China), dissolved in dimethyl sulfoxide (DMSO; Sigma), and added to $2 \mathrm{mg} / \mathrm{mL}$ phosphate-buffered saline (PBS) used as a storage solution. The solution was then added into the cell culture medium at various concentrations. The final concentration of DMSO was $<0.1 \%(\mathrm{v} / \mathrm{v})$ in all experiments. The solutions were stored at $4^{\circ} \mathrm{C}$.

\section{Cell isolation and culture}

Articular chondrocytes were harvested from the joints of Sprague-Dawley (SD) rats or patients with OA. The SD rats were obtained from Guangxi Medical University(Nanning, China). The study protocol was reviewed and approved by the Animal Ethics Committee of Guangxi Medical University Animal Care and Use Committee, China (Protocol number: 2017-03-15). All experiments were carried out following the approved protocol and guidelines. The patients were recruited from the Department of Trauma Surgery, the First Affiliated Hospital of Guangxi Medical University (Nanning, China) between October 10, 2016 to May 2, 2017. The study included fifteen volunteers with OA, which was confirmed by arthroscopy (6 men and 9 women; 60-75-years old) and five control volunteers with knee joint trauma without OA (5 men; 20-35-years old). The volunteers undergoing knee replacement had not received NSAID drug therapy. The diagnosis of OA was based on the America OA Diagnosis Standards (Guidelines for the Treatment of Knee Osteoarthritis in the United States, 2008). The collection and use of human-derived samples were agreed by the donors, with all the procedures approved by the Ethics Committee of the First Affiliated Hospital of Guangxi Medical University (Approval number: 2017(KY-E-040)).

Chondrocytes were separated from the joints of SD rats or volunteers by enzymatic digestion and cultured as described previously [29]. Briefly, the cartilage specimen was cut into pieces followed dissociation with $0.25 \%$ trypsin (Solabio, China) for $30 \mathrm{~min}$, and then incubation with $2 \mathrm{mg} / \mathrm{mL}$ collagenase type II (Gibco, USA) in alpha-modified Eagle's medium ( $\alpha$-MEM; Gibco, USA) for $4 \mathrm{~h}$. After centrifugation at $1000 \mathrm{rpm}$ for $5 \mathrm{~min}$, the chondrocytes were cultured in Dulbecco's MEM (DMEM) High Glucose (Gibco, USA) containing 10\% (v/v) fetal bovine serum (FBS; Zhejiang Tianhang Biotechnology Ltd., China) and 1\% (v/v) penicillin/streptomycin (Solarbio, China), and then incubated at $37^{\circ} \mathrm{C}$ under $5 \% \mathrm{CO}_{2}$. The culture medium was replaced every alternative day. The chondrocytes at the third passage were used for further studies.

\section{Cytotoxicity assay}

Preliminary screening of ART was performed by the 3-(4, 5)-dimethylthiahiazo(-z-y1)-3, 5-diphenytetrazolium-romide (MTT; Gibco) method. The third passage chondrocytes were cultured for $24 \mathrm{~h}$ in 96-well plates $\left(n=5 \times 10^{3}\right)$, and then treated with various concentrations of ART $(0.007-18.0 \mu \mathrm{g} / \mathrm{mL})$ for 3 d. Twenty microliters of $5 \mathrm{mg} / \mathrm{mL}$ MTT were added to each well of the plates and incubated in dark at $37^{\circ} \mathrm{C}$ for $4 \mathrm{~h}$. After the removal of supernatant, $200 \mu \mathrm{L}$ of DMSO was added to dissolve the formazan product. The absorbance of the solution was determined at $570 \mathrm{~nm}$ using a microplate reader (Thermo Fisher Scientific, USA). The optimal dose of ART that favored the growth of cells the most was chosen.

\section{IL-1 $\beta$-induced chondrocytes}

To investigate the effects of ART on IL-1 $\beta$-induced chondrocytes of rat, three groups were formed: (1) normal group, chondrocytes without any treatment; (2) IL-1 $\beta$ group, chondrocytes treated with IL-1 110 $\mathrm{ng} / \mathrm{ml}$, Gibco, USA); and (3) IL-1 $\beta+$ ART group, chondrocytes pre-incubated with ART at the optimal dose for $1 \mathrm{~h}$, followed by stimulation with IL-1 $\beta$ for $48 \mathrm{~h}$. The OA patient-derived chondrocytes were treated with ART at the optimal dose for 2,4 , and $6 \mathrm{~d}$, respectively. To study the association of ART with the Wnt/ $\beta$ catenin signaling pathway, $10 \mathrm{mM}$ lithium chloride (LiCl) (Shanghai Macklin Biochemical Co. Ltd, China), an activator of the Wnt signaling pathway, was introduced. 
Cell viability assay

The viability of chondrocytes was determined by the live/ dead cell viability assay (Thermo Fisher Scientific). Briefly, the cells were rapidly rinsed with PBS, and then incubated with $5 \mu \mathrm{M}$ calcein-AM and 10 $\mu \mathrm{M}$ PI for $5 \mathrm{~min}$ in dark. Subsequently, the dye was quickly removed with PBS and the live/ dead chondrocytes were visualized using a fluorescence imaging microscope (Olympus BX53, Japan).
Table 1. Primer Sequences Used in qRT-PCR Experiments

\begin{tabular}{|c|c|c|}
\hline Gene name & Forward primer & Reverse primer \\
\hline GAPDH H & 5'- GGCTCTCTGCTCCTCCCTGT -3' & 5'- CTGTGCCGTTGAACTTGCCG -3' \\
\hline GADPH R & 5'-TCCAGTATGACTCTACCCACG-3' & 5'-CACGACATACTCAGCACCACCAG -3' \\
\hline CASP3 R & 5'-CGAAATTCGGAGGAGGGGTC-3' & 5'-CTGTCGCTACCTTCCGGTTC-3' \\
\hline CASP3 H & 5'-GGGTTAACCGAAAGGTGGCA-3' & 5'-CTGCAGCATGAGAGTAGGTCA-3' \\
\hline $\mathrm{IL}-1 \beta \mathrm{R}$ & 5'-GCACAGTTCCCCAACTGGTA-3' & 5'-GGAGACTGCCCATTCTCGAC-3' \\
\hline IL-1 $\beta \mathrm{H}$ & 5'-TGAGCTCGCCAGTGAAATGA-3' & 5'-CATGGCCACAACAACTGACG-3' \\
\hline MMP-13 H & 5'-GCCATTACCAGTCTCCGAGG-3' & 5'-TACGGTTGGGAAGTTCTGGC-3' \\
\hline MMP-13 R & 5'-TACCATCCTGCGACTCTTGC-3' & 5'-TTCACCCACATCAGGCACTC-3' \\
\hline FRZB R & 5'-AACTGATGCCAGCGATTCCA-3' & 5'-TGTGGTAAACAGGAGGTCGC-3' \\
\hline FRZB H & 5'-GGCAAAGCAATCAAGCACCA-3' & 5'-ATTAACACCCCAGCGGCTAC-3' \\
\hline TNF-a R & 5'-GGAGGGAGAACAGCAACTCC-3' & 5'-TCTGCCAGTTCCACATCTCG-3' \\
\hline TNF-a H & 5'-TCAGAGGGCCTGTACCTCAT-3' & 5'-GGAGGTTGACCTTGGTCTGG-3' \\
\hline IL-6 R & 5'-AGCCCACCAAGAACGATAGTC-3' & 5'-GTGAAGTAGGGAAGGCCGTG-3' \\
\hline IL-6 H & 5'-TCTGCGCAGCTTTAAGGAGT-3' & 5'-CCCAGTGGACAGGTTTCTGA-3' \\
\hline BAX R & 5'-CATCCAGGATCGAGCAGAGAG-3' & 5'-CAATTCGCCTGAGACACTCG-3' \\
\hline BAX H & 5'-GTCGCCCTTTTCTACTTTGCC-3' & 5'-CGGAGGAAGTCCAATGTCCA-3' \\
\hline Wnt5a H & 5'-TAGCCTGAAGACATGCTGGC-3' & 5'-TGACCTGTACCAACTTGCCC-3' \\
\hline Wnt5a R & 5'-CCACAAGAGACAGCTAGGGC-3' & 5'-CCTAACAGTCCGGTTTGGGT-3' \\
\hline LRP5/6 H & 5'-AGGTCGTCGGTGACAGAGTT-3 & 5'-AGCAAGCATCACGTCCTCTG-3' \\
\hline LRP5/6 R & 5'-CCTGAGTGTGCTGACCAGAG-3' & 5'-AGACAGCATCGCAGCGTAAA-3' \\
\hline GSK-3 $3-\mathrm{R}$ & 5'-GACTAAGGTCTTCCGACCCC-3' & 5'-GCTTGAATCCGAGCATGAGG-3' \\
\hline GSK- $3 \beta \mathrm{H}$ & 5'-GTGGACAGACCAATAACGCC-3' & 5'-CCСACСTCTTGGATCTCCTGA-3' \\
\hline
\end{tabular}

Quantification of intracellular glycosaminoglycan (GAG) secretion

Chondrocytes treated with ART was harvested using proteinase K (Tiangen, China) for digestion. The enzymatic hydrolysates were used in the subsequent biochemical assays as previously described [30]. DNA content was determined by using the Hoechst 33258 (Sigma) method and detected with a spectrofluorometer at 360 (excitation) and $460 \mathrm{~nm}$ (emission), with calf thymus DNA as the standard. The secretion of intracellular glycosaminoglycan (GAG) was measured by the 1, 9-dimethylmethylene blue (DMMB; Sigma) assay. The total intracellular GAG secreted in each sample was detected at $525 \mathrm{~nm}$ with chondroitin sulfate (Sigma) as the standard. Eventually, the content of GAG was normalized to the total DNA content in chondrocytes.

\section{Immunofluorescence staining}

The secretion of IL- $\beta$, TNF-a, BAX, and CASP-3 was detected by immunofluorescence in strict accordance with the instructions. To visualize protein, chondrocytes from rat or human were fixed in $4 \%(\mathrm{w} / \mathrm{v}$ ) paraformaldehyde and treated with Triton X-100. To exclude endogenous peroxidase activity, chondrocytes were treated with $3 \%$ peroxide for $10 \mathrm{~min}$ at $25^{\circ} \mathrm{C}$. The cells were blocked with normal goat serum for $10 \mathrm{~min}$ at room temperature. The samples were incubated with primary antibodies, including IL- $\beta$ (Polyclonal, BOSTER, Wuhan, China; 1:200), TNF-a (Polyclonal, BOSTER; 1:200), BAX (Polyclonal, BOSTER; 1:200), and CASP-3 (Polyclonal, BOSTER; 1:200) overnight at $4^{\circ} \mathrm{C}$. The specimens were then incubated with the secondary antibody IgG-CY3 (BOSTER; $1: 100$ ) for $2 \mathrm{~h}$ at $37^{\circ} \mathrm{C}$ in dark. Eventually, the samples were observed and photographed with an inverted phase contrast microscope (Olympus BX53).

\section{RNA extraction and quantitative real-time PCR}

The intracellular total RNA was extracted using a Hipure Total RNA Mini kit (Magen, China), according to the manufacturer's instructions. Approximately $1000 \mathrm{ng}$ of the extracted RNA was used as a template and reverse transcribed into cDNA using the PrimeScript ${ }^{\mathrm{TM}}$ RT reagent Kit with gDNA Eraser (Takara, China). The quantitative reverse transcription-polymerase chain reaction (qRT-PCR) was performed using a LightCycler ${ }^{\circledR} 480$ (Roche, Germany) with a FastStart Universal SYBR Green Master Mix (Roche, Germany) under the following conditions: $10 \mathrm{~min}$ at $95^{\circ} \mathrm{C}, 15 \mathrm{~s}$ at $95^{\circ} \mathrm{C}$, and $1 \mathrm{~min}$ at $60^{\circ} \mathrm{C}$. The melting curve data were used to verify the specificity of PCR. The relative expression level of genes $(I L-1 \beta, I L-6, T N F-a, M M P$ 13, caspase-3, BAX, $\beta$-catenin, FRZB, Wnt5a, LRP5/6 and GSK-3 $\beta$ ) was determined by the $2^{-\Delta \Delta C t}$ method. The level of target mRNA was normalized to that of glyceraldehyde-3-phosphate dehydrogenase (GAPDH), and compared with that of the control. 


\section{Cellular Physiology Cell Physiol Biochem 2018;51:2575-2590 \begin{tabular}{ll|l} 
and Biochemistry Published onIIne: T1 December 2018 & $\begin{array}{l}\text { (c) } 2018 \text { The Author(s). Published by S. Karger AG, Basel } \\
\text { www.karger.com/cpb }\end{array}$ \\
\hline
\end{tabular} \\ Zhong et al.: Artemisinin Ameliorates Osteoarthritis}

\section{Western blotting}

The total protein from chondrocytes was extracted using a total protein extraction kit, according to the manufacturer's instructions (BOSTER). The concentration of proteins was determined using the BCA Protein Assay reagent (Beyotime, China). Approximately $50 \mu \mathrm{g}$ of the extracted protein was isolated by $10 \%$ (v/v) SDS-PAGE and transferred onto polyvinylidene difluoride (PVDF) membranes (Millipore, Billerica, MA, USA) by electro-blotting. The membranes were then incubated with primary antibodies IL-1 $(1: 100)$, TNF-a (1:100), MMP-13(1:100), caspase-3(1:100), BAX(1:100), $\beta$-catenin (1:100), FRZB (1:100), Wnt5a (1:100), LRP5/6 (1:100), and GSK-3 $\beta$ (1:100) for $2 \mathrm{~d}$ at $4^{\circ} \mathrm{C}$; the primary antibodies were purchased from Boster Biological Technology. The membranes were washed with 1×TBST (Solarbio, Beijing, China) and incubated with an appropriate secondary antibody (Invitrogen, 1:2000) for $2 \mathrm{~h}$. The immunoreactive bands were detected by exposing the blots in a multifunctional imager (GE, USA). The data were normalized against GAPDH for each protein.

\section{Animal procedure}

A total of 30 SD male rats weighing 200-220 g were used. The rat OA model was established as described previously [31], to measure the therapeutic effect of ART in vivo. All experimental procedures were performed in accordance with the Guidelines of the Animal Research Ethics Committee of the Guangxi Medical University. The SD rats received anterior cruciate ligament transection and medial meniscus resection (ACLT+MMx) at the right knee [31]. Briefly, all the rats in the experimental group were anesthetized with $2 \%$ pentobarbital sodium, followed by depilation, disinfection, and spreading of the towel, exposing the right knee joint through the medial patella incision. The patella was dislocated laterally and the knee was placed in the full flexion position, followed by ACL and MCL transection with micro-scissors and resection of the medial meniscus. The rats from the normal group were subjected to sham operations, in which the articular cavities were opened and sutured with the short anterior cruciate ligament intact. Four weeks after surgery, the rats were randomly assigned to two groups, and the ART group was injected with $0.1 \mathrm{~mL}$ of ART $(4.0 \mu \mathrm{g} / \mathrm{mL})$ into the articular cavity once a week. The OA group was injected with $0.1 \mathrm{~mL}$ of PBS as a control alone under the same conditions. After six weeks of therapy, all the rats were euthanized, followed by the collection of synovial fluid for enzyme-linked immunosorbent assay (ELISA) using the ELISA kit (R\&D Systems, USA). The right knees were harvested for further examinations.

\section{Macroscopic observation and histological analysis}

Six weeks after the therapy, the rats were sacrificed and the knee joints were harvested. Macroscopic evaluation was performed by two blinded investigators (YJ and ZL). The erosion of articular cartilage was graded according to the macroscopic score system [32], using a four-grade scale $(0=$ normal-appearing surface, 1 = minimal fibrillation or a slight yellow discoloration of the surface, $2=$ erosion extending to the superficial or middle layers only, $3=$ erosion extending to the deep layers, and $4=$ erosion extending to the subchondral bone). A higher score indicated greater cartilage damage.

The histological evaluation was by Masson's trichrome staining. Briefly, after fixing with 4\% (v/v) paraformaldehyde for $48 \mathrm{~h}$ and decalcifying with EDTA-decalcifying-fluid (Boster), the cartilage tissues were embedded in paraffin and cut into sections of thickness $3 \mu \mathrm{m}$. The sections were dewaxed and detected by Masson staining (Solarbio), according to the instructions. The examination and scoring of each section was performed by three independent researchers (YJ, ZL, and SW) individually. The Osteoarthritis Research Society International (OARSI) Cartilage Histopathology Assessment system was used to evaluate the degenerative status [33].

Quantification of IL-1 $\beta, T N F-a, B A X$, and CASP-3 in vivo

The concentration of total IL-1 $\beta$, TNF-a, BAX, and CASP-3 in synovial fluid was determined using commercially available ELISA kits (R\&D Systems), according to the manufacturer's instructions

\section{Immunohistochemistry}

The secretion of type II collagen (Col2a1), BAX, IL-1 $\beta$, and CASP-3 was assayed by immunohistochemical staining. After washing with PBS, the cells and sections were exposed to $3 \%(\mathrm{v} / \mathrm{v})$ hydrogen peroxide to block any endogenous peroxidase activity for $15 \mathrm{~min}$ at room temperature. The cells and sections were then blocked with normal goat serum for $20 \mathrm{~min}$ at room temperature and incubated with primary antibodies 


\section{Cellular Physiology Cell Physiol Biochem 2018;51:2575-2590 \begin{tabular}{ll|l} 
and Biochemistry Published onlIne: T1 December 2018 & $\begin{array}{l}\text { @ } 2018 \text { The Author(s). Published by S. Karger AG, Basel } \\
\text { www.karger.com/cpb }\end{array}$ \\
\hline
\end{tabular} \\ Zhong et al.: Artemisinin Ameliorates Osteoarthritis}

of types II collagen (BOSTER; 1:200), BAX (BOSTER; 1:200), IL-1 (BOSTER; 1:200), and CASP-3 (BOSTER; $1: 200$ ) overnight at $4^{\circ} \mathrm{C}$. The specimens were subsequently incubated with secondary antibody and biotinlabeled horse radish peroxidase. Antibody binding was then observed using the 3, $3^{\prime}$-diaminobenzidine tetrahydrochloride (DAB) kit (ZSGB-BIO, China), and then counterstained with hematoxylin. Eventually, the cells were gradually dehydrated, sealed with neutral resin, and observed and photographed with an inverted phase contrast microscope (Olympus BX53).

\section{Statistical Analyses}

The results are presented as mean \pm standard deviation. The one-way analysis of variance was performed to determine significant differences, followed by post-hoc test (Turkey's $t$ test). The level of significance was set to $\mathrm{P}<0.05$.

\section{Results}

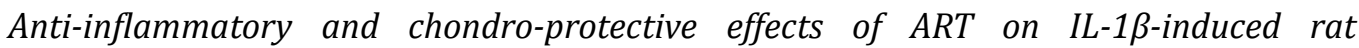
chondrocytes in vitro

Preliminary Screening of ART. Preliminary screening of ART was conducted by the MTT assay. As illustrated in Fig. 1a, ART at concentrations of $0.007-14 \mu \mathrm{g} / \mathrm{mL}$ exhibited negligible cytotoxic effect. Artemisinin at concentrations of $0.125-4.0 \mu \mathrm{g} / \mathrm{mL}$ significantly improves the proliferation of cells $(\mathrm{P}<0.05)$. Thus, $4.0 \mu \mathrm{g} / \mathrm{mL}$ was selected for further investigation; a similar concentration was also used in another study [18].

Proliferation and viability. The proliferation of chondrocytes determined by the MTT assay in different groups is presented in Fig. $1 \mathrm{~b}$. Chondrocytes treated with IL-1 $\beta$ showed a decrease in proliferation (42.35\%), which was enhanced by the pretreatment with ART (4.0 $\mu \mathrm{g} / \mathrm{mL}$ ). The IL-1 $\beta+$ ART group exhibited an increase of $38.63 \%$ compared with that of the IL-1 $\beta$ group at $48 \mathrm{~h}(\mathrm{P}<0.05)$.

The live/dead cell assay by FDA/PI staining revealed that the ART group had more viable cells (green) and less dead cells (red) than those in the IL-1 $\beta$ group (Fig. 1d). This indicates that ART effectively protected the chondrocytes from IL-1 $\beta$ destruction, confirming the results of the MTT assay.

Osteoarthritis-related GAG loss. GAG secreted by intracellular chondrocytes was measured by the DMMB assay. As shown in Fig. 1c, chondrocytes exhibited a 55.98\% decrease in GAG loss after treatment with IL- $1 \beta$ compared with that of the normal group. Artemisinin rescued GAG loss as evidenced by a 78.88\% increase in GAG after treatment with ART compared with that of the IL-1 $\beta$ group at $48 \mathrm{~h}$.

As shown in Fig. 1d, more intense staining with safranin 0 was observed in the IL$1 \beta+$ ART group than in the IL-1 $\beta$ group, which was almost comparable to that in the normal control. The results suggested that the secretion of GAG increased after the treatment with ART, which is in accordance with the biochemical GAG secretion assays.

Expression of OA-related markers. To investigate the anti-inflammatory and chondroprotective effects of ART on IL- $1 \beta$-induced chondrocytes, qRT-PCR was performed to determine the gene expression level of inflammatory markers, including $I L-1 \beta, I L-6, T N F-a$, and $M M P-13$, and apoptotic markers BAX and caspase-3 (Table 1 shows the sequence of primers sequences used in qRT-PCR). As shown in Fig. 1e, chondrocytes treated with IL$1 \beta$ exhibited upregulated expression of $I L-1 \beta, I L-6, T N F-a, M M P-13, B A X$, and caspase- 3 in IL-1 $\beta$-treated cells. In contrast, ART prevented the IL-1 $\beta$-mediated induction of $I L-1 \beta, I L-6$, $T N F-a$, and $M M P-13$, and simultaneously downregulated the expression of BAX and caspase- 3 $(\mathrm{P}<0.05)$. Western blotting further confirmed the qRT-PCR results, as evidenced by the downregulated expression of IL-1 $\beta$, TNF-a, MMP-13, caspase-3, and BAX compared with those in the IL-1 $\beta$ group (Fig. 1f; $\mathrm{P}<0.05$ ). 


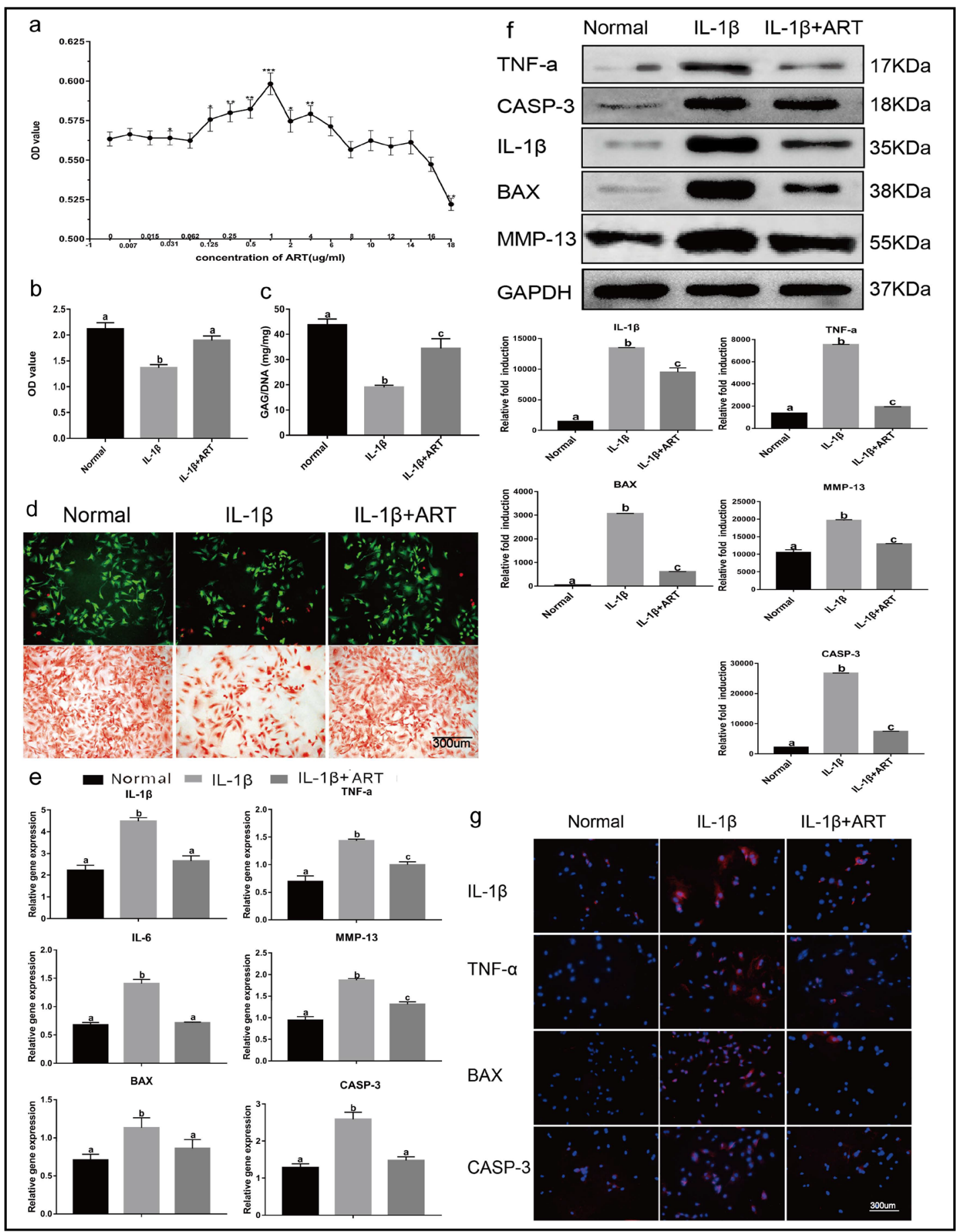

Fig. 1. Chondro-Protective and antiarthritic Effects of ART on IL-1 $\beta$-Induced Chondrocytes in vitro. (a) MTT assay was used to detect the optimum concentration of artemisinin. (values are presented as the means \pm $\mathrm{SD}, \mathrm{n}=6,{ }^{*} \mathrm{P}<0.05,{ }^{* *} \mathrm{P}<0.01,{ }^{* * *} \mathrm{P}<0.001$ ). (b) Cell activity was detected by MTT assay. (c) Quantification of intracellular production of GAG $(n=5)$. (d) FDA/PI stained for cell viability and safranin 0 stained for GAG production. (e) Real-time RT- PCR was performed to determine the gene expression level of IL- $1 \beta$, TNF- $\alpha$, IL-6, MMP-13, BAX, CASP-3. (f) Western blotting was performed to determine the protein expression level of IL-1 $\beta$, TNF- $\alpha$, MMP-13, BAX, CASP-3. (g) Immunofluorescence staining for IL-1 $\beta$, TNF- $\alpha$, BAX and CASP3. Normal (without IL-1 $\beta$ ), IL-1 $\beta$ (with $10 \mathrm{ng} / \mathrm{mL}$ IL-1 $\beta$ ), IL-1 $\beta+A R T$ (with $10 \mathrm{ng} / \mathrm{mL}$ IL-1 $\beta$ and $4 \mathrm{ug} / \mathrm{mL}$ artemisinin). Values are presented as the means $\pm S D, n=6$, different letters denote significances with $\mathrm{P}<0.05$ and the same letter shows no significant differences $(P \geq 0.05)$. 


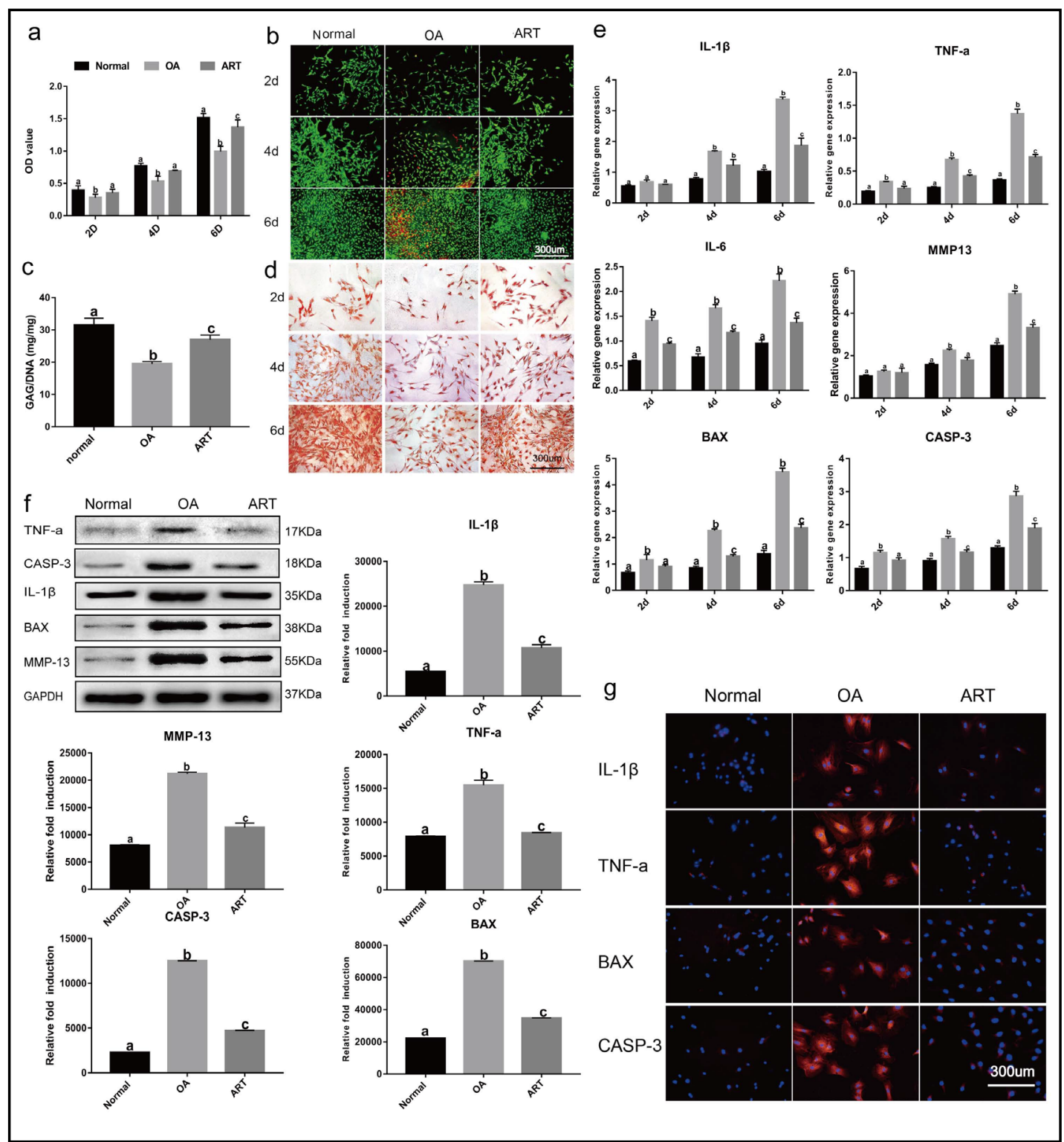

Fig. 2. Chondro-Protective and Antiarthritic Effects of ART on human OA chondrocytes in vitro. (a) MTT assay was implemented to detect the cell activity; (b) FDA/PI staining for cell viability; (c) Quantification of intracellular production of GAG $(n=5)$. (d) Safranin 0 stained for GAG production. (e) Real-time RT- PCR was performed to determine the gene expression level of IL-1 $\beta$, TNF- $\alpha$, IL-6, MMP-13, BAX and CASP-3. (f) Western blot was performed to determine the protein expression level of IL-1 $\beta$, TNF- $\alpha$, MMP-13, BAXand CASP-3. (g) Immunofluorescence staining of IL-1 $\beta$, TNF- $\alpha$, BAX, CASP-3. Normal (normal human chondrocytes), OA (human derived OA chondrocytes), ART (human derived OA chondrocytes treated with $4 \mathrm{ug} / \mathrm{mL}$ artemisinin). Values are presented as the means $\pm \mathrm{SD}, \mathrm{n}=6$, different letters denote significances with $\mathrm{P}<0.05$ and the same letter shows no significant differences $(\mathrm{P} \geq 0.05)$.

The expression of OA-specific and apoptotic proteins in IL-1 $\beta$-induced chondrocytes treated with ART was analyzed by immunofluorescence (Fig. 1g). Positive staining of IL-1 $\beta$, TNF-a, BAX, and caspase- 3 was observed in the IL- $1 \beta$ group, which became less intense after treatment with ART. The results indicate that ART can effectively prevent IL-1 $\beta$-induced inflammation and apoptosis. These results are consistent with the results of qRT-PCR and western blot. 


\section{Cellular Physiology Cell Physiol Biochem 2018;51:2575-2590 \begin{tabular}{ll|l} 
and Biochemistry Published onlIne: T1 December 2018 & $\begin{array}{l}\text { (c) } 2018 \text { The Author(s). Published by S. Karger AG, Basel } \\
\text { www.karger.com/cpb }\end{array}$ \\
\hline
\end{tabular} \\ Zhong et al.: Artemisinin Ameliorates Osteoarthritis}

Anti-inflammatory and chondro-protective effects of ART on human-derived OA chondrocytes in vitro

Proliferation and viability. The proliferation of human OA chondrocytes was evaluated by the MTT assay (Fig. 2a). Compared with that of the normal human chondrocytes, human OA chondrocytes exhibited a decrease of $28.90 \%, 26.32 \%$, and $34.43 \%$ in cell proliferation at days 2,4 , and 6 , respectively ( $<<0.05)$, which was rescued by ART $(4.0 \mu \mathrm{g} / \mathrm{mL})$, evidence by an increase of $26.32 \%, 29.95 \%$, and $37.66 \%$, respectively.

The assessment of cell viability based on FDA/PI staining revealed that less viable cells (green) and more dead cells (red) were present in OA chondrocytes than in the normal group, and ART markedly increased the number of viable cells (Fig. 2b). These results indicate that ART can effectively rescue the growth of OA chondrocytes.

Osteoarthritis-related GAG loss. GAG secretion by human OA chondrocytes treated with ART after $6 \mathrm{~d}$ was measured by the DMMB assay. As shown in Fig. 2c, ART promoted GAG secretion as evidenced by a $38.46 \%$ increase in GAG after treatment with ART compared with that in the OA group.

As shown Fig. 2d, OA chondrocytes showed less intense positive staining with safranin $\mathrm{O}$ than normal cells at each time point, which became more positive after treatment with ART, suggesting that the secretion of GAG increased after the treatment with ART.

Expression of OA markers on human chondrocytes. To investigate the anti-inflammatory and chondro-protective effects of ART on human OA chondrocytes, qRT-PCR was performed to determine the expression level of $I L-1 \beta, I L-6, T N F-a, M M P-13, B A X$, and caspase-3. As shown in Fig. 2e, the expression of inflammatory markers, including $I L-1 \beta, I L-6, T N F-a$, and $M M P$ 13 , and apoptotic markers $B A X$ and caspase- 3 was significantly lower in the ART-treated group than in the OA group $(\mathrm{P}<0.05)$, especially on days 46 . The results indicated that ART inhibited the transcription of inflammatory and apoptotic genes.

The effects of ART on the expression level of OA-related proteins were investigated by WB. In the ART group, the expression of inflammatory markers IL-1 $\beta$, TNF-a, MMP-13, and apoptotic markers BAX and caspase- 3 was significantly inhibited compared with those in the OA group ( $\mathrm{P}<0.05$ ) (Fig. 2f), which confirmed the qRT-PCR results.

The expression of IL-1 $\beta$, TNF- $a$, BAX, and caspase- 3 proteins was detected by immunofluorescence (Fig. $2 \mathrm{~g}$ ). Consistent with the results of qRT-PCR and WB, positive staining of IL-1 $\beta$, TNF-a, BAX, and caspase- 3 was observed in the OA group, whereas, less intense staining was observed in the ART-treated groups. The results indicate that ART can effectively protect human chondrocytes from inflammation and apoptosis.

Effect of ART on ACLT+MMx-induced OA in vivo

Macroscopic observation. An experimental rat OA model fabricated by ACLT+MMx surgery was constructed to assess the effects of ART on the pathological development of OA. In the sham-operation (normal) group, the cartilage on the femoral condyles was normal with a smooth surface and no cartilage defects or osteophyte formation (Fig. 3a). In the OA group, typical characteristics of $\mathrm{OA}$, such as cartilage erosion and osteophyte formation, were observed on the side of the femoral condyles. With time, the damage to cartilage increased. However, the ART group showed less bone wear, cartilage erosion, and osteophyte formation than those in the OA group based on gross appearance in the same period. The macroscopic score of the ART groups reduced by $33.33 \%$ and $35.71 \%$ compared with that of the OA group at 3 and 6 weeks, respectively (Fig. 3b).

Histopathological observation of the articularcartilage. The histopathological observation of cartilage in rats post-surgery included the surface abrasion of cartilage and thickness of cartilage. In the OA group, the apparent degeneration of cartilage was observed, as evidenced by massive loss of superficial cartilage, thinning of the cartilage from the femoral condyles and tibial plateaus, and the loss of proteoglycan (Fig. 3c). However, ART significantly reduced 


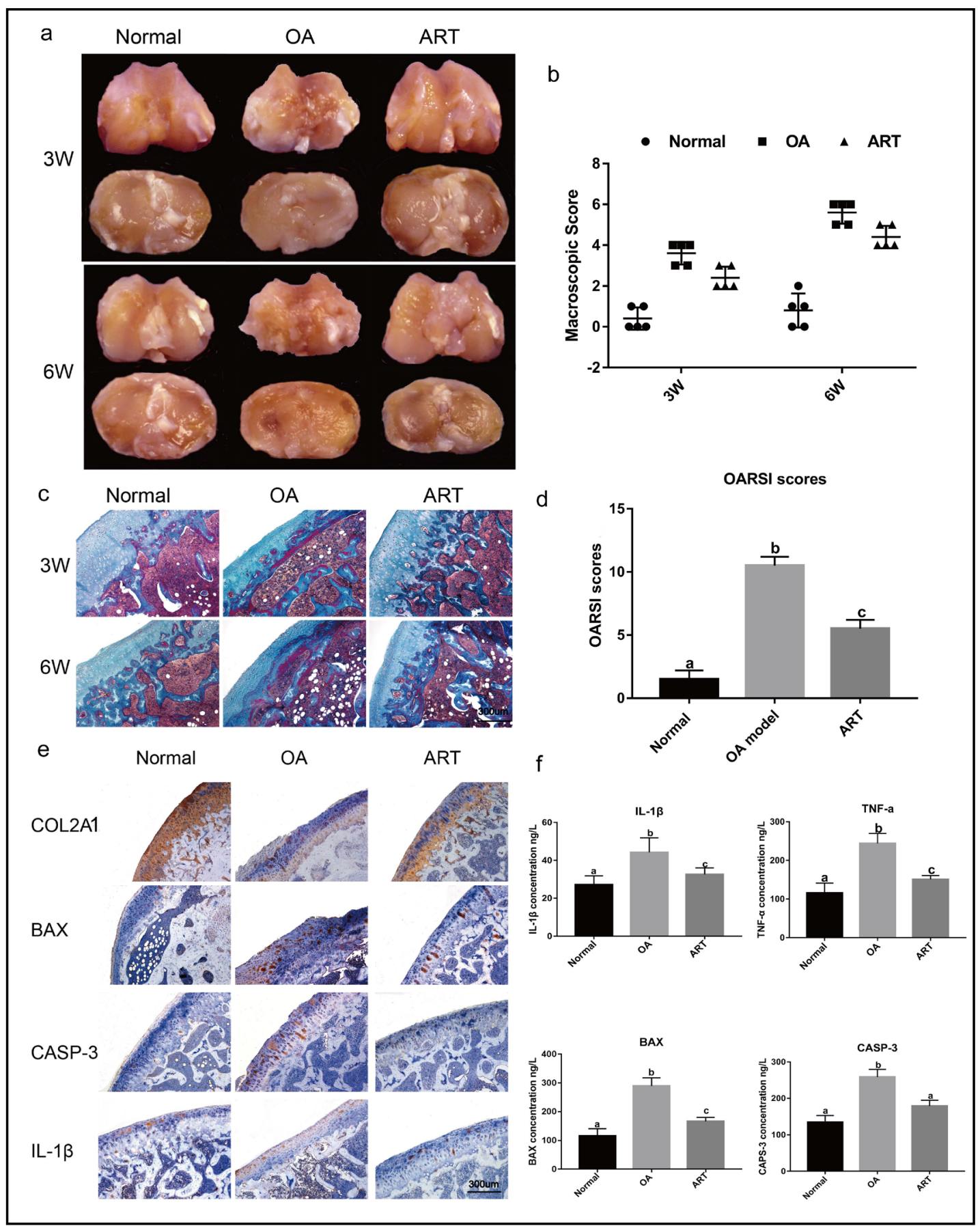

Fig. 3. Effect of ART on the treatment of OA in vivo. (a) Macroscopic appearance. (b) Macroscopic scores. (c) Masson staining was performed in sections of cartilage. (d) Histopathology OARSI System score. (e) Immunohistochemical staining of Col2A1, BAX, CASP-3, IL-1 $\beta$. (f) ELISA was used to analyze protein expression level of IL-1 $\beta$, TNF- $\alpha$, BAX, CASP-3 in joint fluid. OA model group (injected with $0.1 \mathrm{~mL}$ PBS , $\mathrm{n}=5$ ), ART group (injected with $0.1 \mathrm{~mL}$ of ART, $4.0 \mathrm{ug} / \mathrm{mL}, \mathrm{n}=5$ ); Values are presented as the means \pm SD, $\mathrm{n}=5$ joints, different letters denote significances with $\mathrm{P}<0.05$ and the same letter shows no significant differences $(\mathrm{P} \geq 0.05)$. 
Fig. $\quad 4$.

Antiarthritic effect of ART on chondrocytes via the $\mathrm{Wnt} / \beta$ Catenin signaling pathway.

(a) Western blot was used to analyze the proteins of Wnt5a, FRZB, GSK-3 $\beta$ and $\beta$-catenin and (b) qRT-PCR was performed to analyze the gene expression level of Wnt5a, FRZB, LRP5/6 , GSK-3 $\beta$ and $\beta$-catenin in IL$1 \beta$-induced rat chondrocytes. (c) Western blot was used to analyze the proteins of Wnt5a, FRZB, GSK-3 $\beta$ and $\beta$-catenin and (d) qRT-PCR was performed to analyze the gene expression level of Wnt5a, FRZB, LRP5/6, GSK-3 $\beta$ and $\beta$-catenin in human $\mathrm{OA}$ chondrocytes. Values are presented as the means $\pm \mathrm{SD}, \mathrm{n}=5$ joints, different letters denote significances with $\quad \mathrm{P}<0.05$ and the same letter shows no significant differences $(\mathrm{P} \geq$ 0.05).

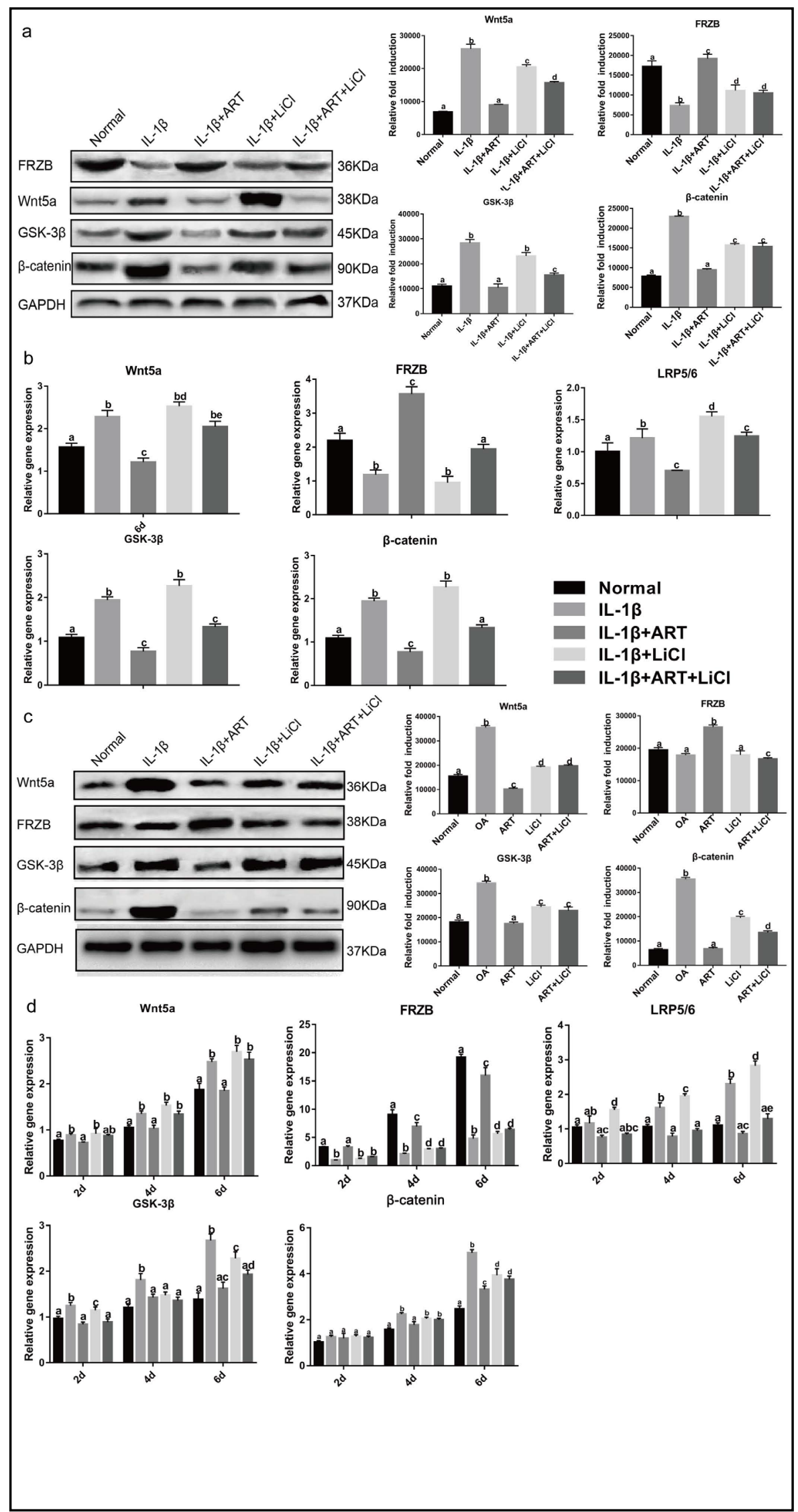


cartilage destruction as evidence by alleviated cartilage structure damage, preserved matrix staining, and reduced number of abnormal cells, although osteophyte proliferation was not reversed (Fig. 3c). The summed histologic score was used to assess cartilage degeneration, and the damage in the ART group was significantly lower than that in the OA group after 6 weeks of therapy $(\mathrm{P}<0.05$ ) (Fig. 3d), which was consistent with the findings of macroscopic observation.

Expression of inflammatory and apoptotic markers in vivo. In specimens of cartilage from the tibial plateau, chondrocytes in the superficial layers were detected by immunohistochemical staining of Col2a1, BAX, IL-1 $\beta$, and CASP-3 (Fig. 3e). More positive staining of Col2a1, a cartilage-specific marker, was observed in the ART group than in the OA group. However, in the OA group, large areas of strong positive staining of IL-1 $\beta, B A X$, and $\beta$-catenin was observed in the middle and deep cartilage layers compared with those in the normal group. Less positive staining was observed in the shallow and middle cartilage layers, and most of the cartilage tissue remained intact in the ART group.

The expression level of inflammation and apoptosis markers in vivo after 6-weeks of treatment was also detected by the ELISA (Fig. 3f). The expression of inflammatory markers IL-1 $\beta$ and TNF-a, and apoptotic markers BAX and caspase- 3 was significantly higher in the OA group than in the normal cartilage. After treatment with ART, the expression of IL-1 $\beta$, TNF-a, $\mathrm{BAX}$, and caspase- 3 was significantly reduced when compared with those in the OA group $(\mathrm{P}<0.05)$. These results suggest that ART effectively ameliorated OA by downregulating inflammation and apoptosis in vivo.

Antiarthritic effect of ART via the Wnt/ $\beta$-catenin signaling pathway

In IL- $1 \beta$-induced rat chondrocytes, the expression of $\beta$-catenin, Wnt5a, and GSK- $3 \beta$ was upregulated, whereas that of FRZB was downregulated compared with those in the normal group (Fig. 4a). After treatment with ART, the expression of $\beta$-catenin, Wnt5a, and GSK-3 $\beta$ was significantly downregulated and FRZB was upregulated. Lithium chloride promoted $\beta$-catenin translocation to the nucleus to activate the Wnt/ $\beta$-Catenin signaling pathway and effectively promoted the expression of $G S K-3 \beta$, Wnt $5 a$, and $L R P 5 / 6$. However, ART reduced the

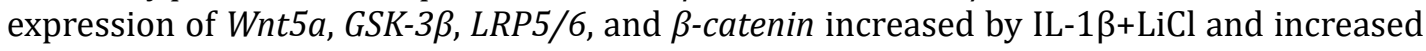
the expression of FRZB (Fig. 4b).

In human-derived OA chondrocytes, the expression of Wnt5a, GSK-3 $\beta$, and LRP5/6 was upregulated and FRZB was downregulated compared with those in the normal human chondrocytes (Fig. 4c). As expected, ART reduced the expression of Wnt5a, GSK-3 $\beta, L R P 5 / 6$, and $\beta$-catenin increased by LiCl and increased the expression of FRZB in human chondrocytes (Fig. 4d). These results indicate that ART ameliorates osteoarthritis by suppressing the Wnt/ $\beta$-Catenin signaling pathway.

\section{Discussion}

Currently, NSAIDs are the main clinically used drugs for OA. However, NSAIDs are limited by their side effects, such as ease of suppression, limited clinical remission rate, and immunity [3]. Due to the minimal side effects and potent anti-inflammatory activity, ART is used to treat $\mathrm{OA}$ in the present study.

Artemisinin exhibited potent anti-inflammatory effect by inhibiting the expression of pro-inflammatory chemokines and cytokines, such like IL-1 $\beta$, IL-6, TNF-a, and MMP-13, in both IL-1 $\beta$-induced OA chondrocytes of rats and cells derived from patients with OA (Fig. 1eg, Fig. 2e-g). It also ameliorated ACLT-injured cartilage degradation by downregulating the expression of inflammatory markers (IL-1 $\beta$ and TNF-a) (Fig. 3f). Interleukin-1 $\beta$ and TNF-a are predominant cytokines regulating the production of multifarious pro-inflammatory cytokines, such as IL-6 and IL-8, for the initiation of inflammation cascades [34]. These cytokines also function as catabolic factors in cartilage destruction via the activation of 
proteinases (MMPs and aggrecanases) [35]. MMP-13 is a major enzyme responsible for the degradation of type II collagen in OA [36]. In the present study, ART downregulated the expression of pro-inflammatory cytokines elevated in IL-1 $\beta$-treated chondrocytes and ACLTstimulated joints (Fig. 1e, Fig. 2e, Fig. 3f.), which effectively reduced the expression of MMPs and rescued the subsequent degradation of articular cartilage matrix. It also decreased the expression of inflammatory markers in OA patient-derived chondrocytes, which holds promise in OA therapy.

Artemisinin has favorable biocompatibility and chondro-protective potential as evidenced by enhanced cell proliferation and viability, and GAG deposition in both IL-1 $\beta$ treated (Fig. 1b-d) and human OA-derived chondrocytes (Fig. 2a-d). It has been reported that ART has minimal cytotoxicity against normal cells [37]. Artemisinin also prevented ACLT-induced cartilage degradation by upregulating the expression of cartilage specific marker Col2a1. The chondro-protective effect of ART might be associated with its role in the prevention of chondrocyte apoptosis. Accumulating evidence suggests that chondrocyte apoptosis plays an important role in the development and progression of OA [38, 39]. During the repair process, the apoptotic cells represented by an increased survival of chondrocytes might be a protection mechanism. Upon activation of apoptosis, ART leads to the stimulation of caspase cascade, including caspase-2, caspase-3, and caspase-9, and subsequently the cellular components are dismantled resulting in cell death [40,41]. The extrinsic pathway is induced by death receptor signaling ligands, such as FasL, TNFa, and tumor necrosis factor-related apoptosis-inducing ligand (TRAIL) [42]. TRAIL determines the activation of the extrinsic pathway, and bind to its death receptors DR4 and DR5 and induce caspase-8 initiator protease, which activates executioner proteases, such as caspase-3 [43]. In the present study, we observed that ART blocked chondrocyte apoptosis as evidenced by the downregulation of expression of intrinsic pathway markers BAX and caspase-3 (Fig. 1e-g, Fig. 2e-g), demonstrating the chondro-protective potential of ART.

Notably, Wnt/ $\beta$-catenin signaling, which contributes to the extracellular matrix damage process and chondrocyte destruction in the etiology and pathogenesis of $\mathrm{OA}[22,23]$, was effectively inhibited by ART. Some FDA-approved drugs, such as verapamil, are Wnt antagonists which hold promise in OA therapy [44]. FRZB, an original antagonist of Wnt signaling [25] identified as a chondrogenic factor in articular cartilage extracts, has been studied in $\mathrm{OA}$ animal models and patients with $\mathrm{OA}$ as a modulator of Wnt signaling [23]. In the present study, ART markedly inhibited the activation of Wnt/ $\beta$-catenin signaling as evidenced by the upregulation of FRZB in IL-1 $\beta$-induced chondrocytes and downregulation of the expression of $\beta$-catenin (Fig. 5), which induces the expression of inflammatory cytokines,

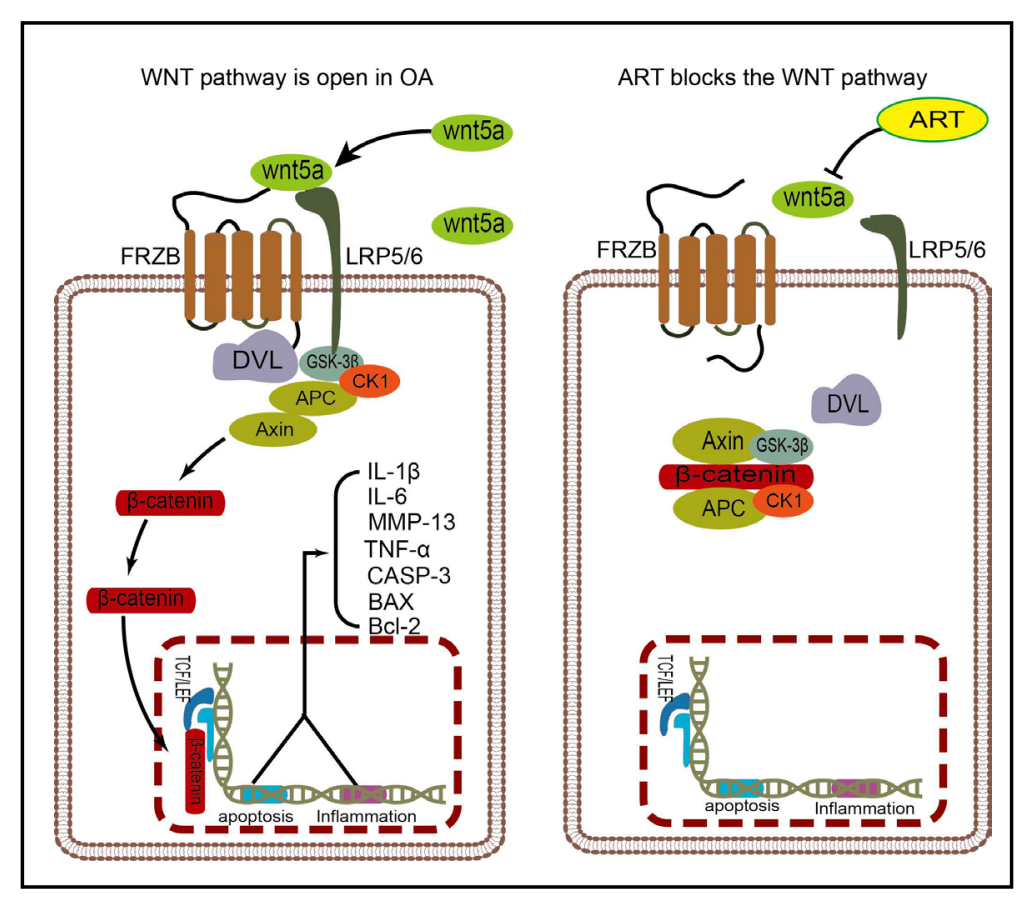

Fig. 5. Schematic description of the Wnt/ $\beta$-catenin signaling pathway regulated by ART during the process of OA. 


\section{Cellular Physiology Cell Physiol Biochem 2018;51:2575-2590 \begin{tabular}{ll|l} 
and Biochemistry & $\begin{array}{l}\text { DOI: 10.1159/000495926 } \\
\text { Published online: II December } 2018\end{array}$ & $\begin{array}{l}\text { @ } 2018 \text { The Author(s). Published by S. Karger AG, Basel } \\
\text { www.karger.com/cpb }\end{array}$ \\
\cline { 1 - 3 }
\end{tabular} \\ Zhong et al.: Artemisinin Ameliorates Osteoarthritis}

chemokines, and apoptosis-related factors in human OA chondrocytes [45]. Accompanied with the downregulation of $\beta$-catenin, the expression of $G S K-3 \beta, W n t 5 a$, and LRP5/6 was downregulated. Artemisinin also rescued the matrix damage process and aggravated chondrocyte destruction by $\mathrm{LiCl}$, which is an activator of Wnt/ $\beta$-catenin signaling pathway that can upregulate the expression of $\beta$-catenin, GSK-3 $\beta, W n t 5 a$, and $L R P 5 / 6$. These results indicate that ART might inactivate Wnt/ $\beta$-catenin signaling. They also confirm that ART serves as a favorable Wnt/ $\beta$-catenin antagonist to protect chondrocytes from destruction in patients with OA. We also demonstrated that ART derived from natural herbs exerted antiinflammatory and chondro-protective effects in the treatment of IL-1 $\beta$-induced chondrocytes and $\mathrm{OA}$ patient-derived chondrocytes. It also protected cartilage from the destruction in ACLT-injured joints. The effect of ART on OA might be associated with the inhibition of Wnt/ $\beta$-catenin signaling pathway. The results of the present study suggest the potential of ART in the treatment of OA.

\section{Conclusion}

In conclusion, ART alleviates IL-1 $\beta$-mediated inflammatory response and OA progression by regulating the Wnt/ $\beta$-catenin signaling pathway. Thereby, it might be developed as a potential therapeutic agent for OA. However, the effect and mechanism of action of ART should be further explored, as the present study was limited in terms of number of animals, OA score, etc. Especially, the clinical application of ART should be investigated.

\section{Acknowledgements}

This work has been financially supported by National key research and development program of China (2018YFC1105900), National Natural Science Fund of China (Grant No. 8176090039, 81760326), the Guangxi Scientific Research and Technological Development Foundation (Grant No. GuikeAB16450003), and the Project of innovation entrepreneurship base of Guangxi Medical University (Grant No. GCICB-IE-2017011).

\section{Disclosure Statement}

The authors confirm that this article content has no conflicts of interest.

\section{References}

1 Parkinson L, Waters DL, Franck L: Systematic review of the impact of osteoarthritis on health outcomes for comorbid disease in older people. Osteoarthritis cartilage 2017;25:1751-1770.

-2 Musumeci G, Castrogiovanni P, Trovato FM, Imbesi R, Giunta S, Szychlinska MA, Loreto C, Castorina S, Mobasheri A: Physical activity ameliorates cartilage degeneration in a rat model of aging: A study on lubricin expression. Scand J Med Sci Sports 2015;25:e222-e230.

-3 da Costa BR, Reichenbach S, Keller N, Nartey L, Wandel S, Jüni P, Trelle S: Effectiveness of non-steroidal anti-inflammatory drugs for the treatment of pain in knee and hip osteoarthritis: a network meta-analysis. Lancet 2017;390:e21-e33.

-4 Lapane KL, Yang S, Driban JB, Liu SH, Dube CE, McAlindon TE, Eaton CB: Effects of prescription nonsteroidal antiinflammatory drugs on symptoms and disease progression among patients with knee osteoarthritis. Arthritis Rheumatol 2015;67:724-732.

5 Breivik H: NSAIDs relieve osteoarthritis (OA) pain, but cardiovascular safety in question even for diclofenac, ibuprofen, naproxen, and celecoxib:what are the alternatives? Scand J Pain 2017;16:148-149. 


\section{Cellular Physiology Cell Physiol Biochem 2018;51:2575-2590 and Biochemistry \begin{tabular}{l|l} 
DOI: $10.1159 / 000495926$ & (c) 2018 The Author(s). Published by S. Karger AG, Basel \\
Publisher 2018
\end{tabular}

6 Musumeci G, Maria Trovato F, Imbesi R, Castrogiovanni P: Effects of dietary extra-virgin olive oil on oxidative stress resulting from exhaustive exercise in rat skeletal muscle: a morphological study. Acta Histochem 2014;116:61-69.

7 Zhuang C, Wang Y, Zhang Y, Xu N: Oxidative stress in osteoarthritis and antioxidant effect of polysaccharide from angelica sinensis. Int J Biol Macromol 2018;115:281-286.

8 Tu Y: Artemisinin A Gift from Traditional Chinese Medicine to the World (Nobel Lecture). Angew Chem Int Ed Engl 2016;55:10210-10226.

-9 Talisuna AO, Karema C, Ogutu B, Juma E, Logedi J, Nyandigisi A, Mulenga M, Mbacham WF, Roper C, Guerin PJ, D’Alessandro U, Snow RW: Mitigating the threat of artemisinin resistance in Africa: improvement of drug-resistance surveillance and response systems. Lancet Infect Dis 2012;12:888-896.

10 Nayyar GML, Breman JG, Newton PN, Herrington J: Poor-quality antimalarial drugs in southeast Asia and sub-Saharan Africa. Lancet Infect Dis 2012;12:488-496.

11 Golenser J, Waknine JH, Krugliak M, Hunt NH, Grau GE: Current perspectives on the mechanism of action of artemisinins. Int J Parasitol 2006;36:1427-1441.

12 Mercer AE, Maggs JL, Sun XM, Cohen GM, Chadwick J, O’Neill PM, Park BK: Evidence for the involvement of carbon-centered radicals in the induction of apoptotic cell death by artemisinin compounds. J Biol Chem 2007;282:9372-9382.

13 Bhaw-Luximon A, Jhurry D: Artemisinin and its derivatives in cancer therapy: status of progress, mechanism of action, and future perspectives. Cancer Chemother Pharmacol 2017;79:451-466.

14 Efferth T: From ancient herb to modern drug: Artemisia annua and artemisinin for cancer therapy. Semin Cancer Biol 2017;46:65-83.

15 Slezakova S, Ruda-Kucerova J: Anticancer Activity of Artemisinin and its Derivatives. Anticancer Res 2017;37:5995-6003.

16 Canivet C, Menasria R, Rheaume C, Piret J, Boivin G: Valacyclovir combined with artesunate or rapamycin improves the outcome of herpes simplex virus encephalitis in mice compared to antiviral therapy alone. Antiviral Res 2015;123:105-113.

17 Hou L, Huang H: Immune suppressive properties of artemisinin family drugs. Pharmacol Ther 2016;166:123-127.

18 Shi C, Li H, Yang Y, Hou L: Anti-inflammatory and immunoregulatory functions of artemisinin and its derivatives. Mediators Inflamm DOI: 10.1155/2015/435713.

19 Hou L, Block KE, Huang H: Artesunate abolishes germinal center B cells and inhibits autoimmune arthritis. PLoS ONE DOI: 10.1371/journal.pone.0104762. eCollection 2014.

20 Wang JX, Tang W, Zhou R, Wan J, Shi LP, Zhang Y, Yang YF, Li Y, Zuo JP: The new water-soluble artemisinin derivative SM905 ameliorates collagen-induced arthritis by suppression of inflammatory and Th17 responses. Br J Pharmacol 2009;153:1303-1310.

21 Arjen B. Blom, Peter L. van Lent, Kraan PMvd, Berg WBvd: To Seek Shelter from the Wnt in Osteoarthritis? Wnt-Signaling as a Target for Osteoarthritis Therapy. Curr Drug Targets 2010;11:620-629.

-22 Zhou Y, Wang T, Hamilton JL, Chen D: Wnt/beta-catenin Signaling in Osteoarthritis and in Other Forms of Arthritis. Curr Rheumatol Rep 2017;19:53.

23 Corr M: Wnt-beta-catenin signaling in the pathogenesis of osteoarthritis. Nat Clin Pract Rheumatol 2008;4:550-556.

24 Sassi N, Laadhar L, Allouche M, Achek A, Kallel-Sellami M, Makni S, Sellami S: WNT signaling and chondrocytes: from cell fate determination to osteoarthritis physiopathology. J Recept Signal Transduct Res 2014;34:73-80.

25 Jiang T, Zhou B, Huang L, Wu H, Huang J, Liang T, Liu H, Zheng L, Zhao J: Andrographolide Exerts ProOsteogenic Effect by Activation of Wnt/ $\beta$-Catenin Signaling Pathway in vitro. Cell Physiol Biochem 2015;36:2327-2339.

26 Shi S, Man Z, Li W, Sun S, Zhang W: Silencing of Wnt5a prevents interleukin-1beta-induced collagen type II degradation in rat chondrocytes. Exp Ther Med 2016;12:3161-3166.

-27 Zhu M, Tang D, Wu Q, Hao S, Chen M, Xie C, Rosier RN, O’Keefe RJ, Zuscik M, Chen D: Activation of $\beta$-Catenin Signaling in Articular Chondrocytes Leads to Osteoarthritis-Like Phenotype in Adult $\beta$-Catenin Conditional Activation Mice. J Bone Miner Res 2009;24:12-21.

-28 Wu J, Ma L, Wu L, Jin Q: Wnt-beta-catenin signaling pathway inhibition by sclerostin may protect against degradation in healthy but not osteoarthritic cartilage. Mol Med Rep 2017;15:2423-2432. 


\section{Cellular Physiology Cell Physiol Biochem 2018;51:2575-2590

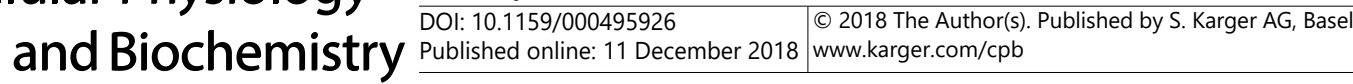 \\ Zhong et al.: Artemisinin Ameliorates Osteoarthritis}

29 Lu Z, Wu H, Lin X, Liu B, Lin C, Zheng L, Zhao J: Chondro-Protective and Antiarthritic Effects of SulfonamidoBased Gallate-ZXHA-TC in vitro and in vivo. ACS Chem Biol 2016;11:1613-1623.

30 Jiang T, Xu G, Wang Q Yang L, Li Z, Zhao J, Zhang X: In vitro expansion impaired the stemness of early passage mesenchymal stem cells for treatment of cartilage defects. Cell Death Dis DOI: 10.1038/ cddis.2017.215.

-31 Hayami T, Pickarski M, Zhuo Y, Wesolowski GA, Rodan GA, Duong LT: Characterization of articular cartilage and subchondral bone changes in the rat anterior cruciate ligament transection and meniscectomized models of osteoarthritis. Bone 2006;38:234-243.

32 Pauli C, Grogan SP, Patil S, Otsuki S, Hasegawa A, Koziol J, Lotz MK, D’Lima DD: Macroscopic and histopathologic analysis of human knee menisci in aging and osteoarthritis. Osteoarthritis and cartilage 2011;19:1132-1141.

-33 Pritzker KP, Gay S, Jimenez SA, Ostergaard K, Pelletier JP, Revell PA, Salter D, Wb VDB: Osteoarthritis cartilage histopathology: grading and staging. Osteoarthritis Cartilage 2006;14:13-29.

-34 Nguyen L, Sharma A, Chakraborty C, Saibaba B, Ahn M-E, Lee S-S: Review of Prospects of Biological Fluid Biomarkers in Osteoarthritis. Int J Mol Sci 2017;18:601.

35 Daheshia M, Yao JQ: The Interleukin $1 \beta$ Pathway in the Pathogenesis of Osteoarthritis. J Rheumatol 2008;35:2306.

-36 Gooljarsingh LT, Lakdawala A, Coppo F, Luo L, Fields GB, Tummino PJ, Gontarek RR: Characterization of an exosite binding inhibitor of matrix metalloproteinase 13. Protein Sci 2008;17:66-71.

-37 Hou J, Wang D, Zhang R, Wang H: Experimental Therapy of Hepatoma with Artemisinin and Its Derivatives: In vitro and In vivo Activity, Chemosensitization, and Mechanisms of Action. Clin Cancer Res 2008;14:55195530 .

38 Musumeci G, Castrogiovanni P, Trovato FM, Weinberg AM, Al-Wasiyah MK, Alqahtani MH, Mobasheri A: Biomarkers of Chondrocyte Apoptosis and Autophagy in Osteoarthritis. Int J Mol Sci 2015;16:2056020575.

39 Hwang HS, Kim HA: Chondrocyte Apoptosis in the Pathogenesis of Osteoarthritis. Int J Mol Sci 2015;16:26035-26054

40 Zhao Y, Jing Z, Li Y, Mao W: Berberine in combination with cisplatin suppresses breast cancer cell growth through induction of DNA breaks and caspase-3-dependent apoptosis. Oncol Rep 2016;36:567-572

41 Grosse L, Wurm CA, Bru ser C, Neumann D, Jans DC, Jakobs S: Bax assembles into large ring-like structures remodeling the mitochondrial outer membrane in apoptosis. EMBO J 2016;35:402-413.

-42 Musumeci G, Loreto C, Carnazza ML, Martinez G: Characterization of apoptosis in articular cartilage derived from the knee joints of patients with osteoarthritis. Knee Surg Sports Traumatol Arthrosc 2011;19:307313.

43 Musumeci G, Loreto C, Carnazza ML, Strehin I, Elisseeff J: OA cartilage derived chondrocytes encapsulated in poly(ethylene glycol) diacrylate (PEGDA) for the evaluation of cartilage restoration and apoptosis in an in vitro model. Histol Histopathol 2011;26:1265-1278.

-44 Akira Takamatsu, Bisei Ohkawara, Mikako Ito, Akio Masuda, Tadahiro Sakai, Naoki Ishiguro, Ohno K: Verapamil protects against cartilage degradation in osteoarthritis by inhibiting Wnt/ $\beta$-catenin signaling. PLoS One DOI: 10.1371/journal.pone.0092699.

-45 Zhang Z, Xing X, Hensley G, Chang LW, Liao W, Abu-Amer Y, Sandell LJ: Resistin induces expression of proinflammatory cytokines and chemokines in human articular chondrocytes via transcription and messenger RNA stabilization. Arthritis Rheum 2010;62:1993-2003. 